\title{
Transcending vulnerability: fashioning a remedy from mortality itself
}

Peter Hampson

"The kiss of the angel of death awakens posthumous mind to the thought of God»

William Desmond ${ }^{1}$

\section{Dimensions of human vulnerability}

Whether an immortal would be invulnerable is debatable, ${ }^{2}$ whether a mortal being is vulnerable is not. To live suspended above the void, in the face of inescapable death, is to be inevitably rat risk . All humans are vulnerable and die, and vulnerable because they die. They are woundable and in turn wound ${ }^{3}$ by virtue of their very existence. To say we are vulnerable in all aspects of our personhood is unhelpful. Equally, to try to itemize each one of these is unmanageable in so short a piece. An intermediate way is to think of the human being as existing in an envelope defined by three important axes.

First, we are human beings, entities in the world, animals made from stardust, marked by our physicality and materiality, but we are also human beings, creatures characterised by our language, our reflexivity, our empathy, our cultures. Our first ontological axis or dimension thus stretches through matter to mind, from nature to culture, from animal to angel. It picks out a continuum (or related set of continua); it is not a dichotomy. Converging scholarship from fields as diverse as psychology, evolutionary biology, theology, and politics reminds

\footnotetext{
1 William Desmond, God and the Between, Oxford 2008, 33.

2 The question >does God suffer has of course been debated in the theological literature. See, for example, Jurgen Moltmann, The Crucified God, London 1974 and Thomas G. Weinandy, Does God Suffer?, London 2000.

3 Vulnerability is a double-edged sword. From vulnerabilis (wounding), ,vulnerable is first defined by the Oxford English Dictionary as having power to wound; wounding. Only then, in its second definition does the dictionary mention that (which) may be wounded; susceptible of receiving wounds . The vulnerable, in the commonly used sense, are already wounded, often by other damaged creatures, but if the wisdom of the language is sound, they will be just as likely to wound themselves and others through their default responses and behaviours.
} 
us that culture is natural, and that nature is encultured or cultivated. As embodied and embedded creatures, we are thus not separately and differentially vulnerable in our animal and physical versus our mental, cultural, spiritual aspects. Damage to our status as cultural and spiritual animals frequently results in damage to our materiality, to our health, our physical well-being. So too, poverty, deprivation, poor living conditions, unwise health behaviours, all have consequences for our mental, cultural, and spiritual flourishing.

But as well as being suspended vertically< between matter and spirit, we are also time-locked creatures who are born, grow, develop, mature, and die. A second important ontological axis is the temporal or diachronic one. This implicates issues of lifespan development including our coming into being, our physical growth, our psychological development, including the emergence of self and self awareness, attachment, memory, future prospection and so on. Again, there is no single or simple place on this dimension where we are uniquely vulnerable, though certain critical periods, such as the early years, adolescence, mid life, and end of life may for some present unique and pressing challenges. Time itself underwrites the transiency and fragility of our existence; its paradoxical quality as the present is always slipping away into the past, and the future is yet to come, as we know; yet time also illustrates our embodied and embedded transcendence, here but possibly there, now but not yet.

Finally, we are inherently social, or more generally, relational beings, suggesting our third horizontal axis. Between self and other, we are incapable of survival let alone flourishing alone. As infants we need the care of others for our physical, emotional, social, and cultural well-being. We are not individuals or solipsistic selves who learn to be connected, but social creatures learning as a result of our connectivity to be individuals and persons in our own right. This aspect of the person is governed not by an internal property or a Cartesian I $<$, but associated with a rrelational self constituted by and for its connections with the world and with others. But our conspecifics can also be a threat or danger just as can our culture, our materiality, and our temporality. ${ }^{4}$

Although conceptually distinguishable, these axes are by no means orthogonal since change in one invariably implies change in another. Moreover, our spiritual nature is not to be located simply on the first axis, but is a dimension encompassing them all. By

\footnotetext{
4 "... to pursue relationality [...] is to risk being wounded by the other«, John Milbank/Adrian Pabst, Politics of Virtue: Post-liberalism and the Human Future, London 2016,80 .
} 
deepening our spiritual engagement the quality if not number of our social connections is likely to grow and develop, whereas with its weakening they might diminish through time. This is not to state, in a facile sense, that sspiritual people are often (though not inevitably) religious, and that religion, actively engaged in, inclines us to positive social interaction with our fellows. It is rather that spiritual awareness often (though again not invariably) carries with it a growing awareness of the interconnectedness of all things, of all in all. Indeed some might argue that relationality is a fifth and neglected transcendental along with beauty, truth, goodness, and being with which it is convertible. Conversely, a reduction in spiritual engagement often means a concomitant increase in the belief in pure nature, in a dead and commodified world, in people as objects not subjects. Time, too, is an axis implicated with relationality, with our temporal selves, the world and others, bringing more or less potential for spiritual enrichment or impoverishment. We can be locked into the present, a slave to the past, or live only for the future, or we can be free to engage with the eternal which transcends the now, bringing the past, present, and future to bear on our imagined possibilities. Through time, we deepen our engagements with being, or lessen them.

The self, then, is bounded in these ways as it navigates physical, social, cultural, and spiritual worlds. It experiences vulnerability along these three dimensions as challenges to relationality, disorders and disjunctions of culture and nature, and impediments to full development flourishing. In the limit case, such vulnerability implicates the very existence of the self. It would be surprising, therefore, if our species had failed to develop characteristic ways of dealing with this, ways in which we adjust or cope to manage this strange existence as we walk the tightrope between being and non-being. What then are these default psychological responses to our vulnerability; how are they related to our ınormal moral and ethical sensibilities; what, if any, are the compensatory means available to us to deal with them? What role might religion and spirituality play in all this? 


\section{Mortal terror and psychological >default settings`}

Psychotherapist Ernest Becker's work is somewhat neglected nowadays though his book, The Denial of Death, was awarded the Pulitzer prize for non-fiction, some two months after his death in $1974 .{ }^{5}$ Becker's psychoanalytic thesis is that human cultural systems are essentially an outcome of defence mechanisms constructed to protect us from fear of our own mortality. By encouraging a focus on the symbolic meanings, which characterize our cultural selves, culture helps us, he argued, to repress or at least obscure the knowledge of our physical mortality, achieve an immortality of sorts, and thus reduce the anxiety that inevitably accompanies our awareness of death.

But for the work of empirical psychologists Sheldon Solomon, Jeff Greenberg and Tom Pyszczynski Becker's ideas would most likely have been forgotten. Now, 25 years of empirical research and over 200 empirical studies later, there is a great deal of converging evidence for Becker's theoretical views. Recast as >Terror Management Theory< (TMT), Solomon et al have examined death awareness and its effects from a socio-cognitive perspective. ${ }^{6}$ By manipulating people's tacit awareness of their mortality or increasing what they term 'mortality saliences, they have revealed a number of reliable and resistant human psychological responses. Chief among these is that when reminded explicitly or otherwise of their mortality, people attempt to increase their self-esteem to try to bolster or affirm their existential security. Often this is achieved by asserting the validity of one's in-group, over and against the out-group, and through a fetishistic clinging to familiar group, cultural, and religious systems. TMT research has shown how even implicit death reminders have these dramatic effects, and, conversely, how threatening the self or attacking a revered cultural group induce increased fear of mortality. As an example, even cursory inspection of the group dynamics in the recent UK referendum on the EU suggests that such responses were in play especially though not only among those voting to sleaver the EU. Feeling threatened and vulnerable in many ways, ${ }^{7}$ such individ-

\footnotetext{
5 Ernest Becker, The Denial of Death, New York 1973.

6 Sheldon Solomon/Jeff Greenberg/Tom Pyszczynski, The Worm at the Core: On the Role of Death in Life, London 2015.

7 The demographics of those voting >Brexit< (the vote to leave Europe) included a disproportionate number of older voters ( $>40$ years), those with no higher education, and those on low incomes living in the post-industrial areas ravaged by 30 years of neoliberal economic policy. Among the various campaign messages that appear to have swayed this group was the promise that a no vote would allow the UK sto take back controk, though from what or whom to do what was never made fully clear.
} 
uals were (mis)-led by leaders who not only affirmed the validity of all things British, but offered in tandem role models of puffed up self aggrandizement. The resulting potential closure of borders, minds, and culture at the time of writing now threatens us all.

Are such responses to threat inevitable? Through some lenses it might seem so. Fear and anger, (and sorrow to an extent?) lurk close to the surface in TMT dynamics - fear of injury, fear of loss of status, fear of attack on what one holds dear - and it is commonplace to note that negative emotions like these tend to close down the self across all its dimensions. We draw back, we defend, we shrink our boundaries. In Charles Taylor's terms we might say we become more suffered ${ }^{8}$ Examples of this response style abound beyond the insular dynamics of those who voted sleave or sbrexit in the UK referendum. ${ }^{9}$ We might also point to the braggadocio of the successful candidate in the recent US presidential election, and his 'Make America Strong Again sentiments feted by the vulnerable voters who championed him. Similar self protective reactions are also abundantly clear in the dispossessed, working class cage fighters, and, intriguingly, in the apparently self assured police, and the privileged city bankers, recently skillfully interviewed and creatively depicted by artist Grayson Perry on UK's Channel $4 \mathrm{TV}^{10}$ In their different ways all attempt to bolster their challenged masculinity in the face of

Other motivations appeared to be the fear that continued immigration would threaten or steal jobs otherwise available for locals, that the EU was responsible in no small part for the increased bureaucracy and managerialism experienced in the last 20 years, and that the economy would not suffer from leaving.

8 Charles Taylor, A Secular Age, London 2007.

9 The dispossessed did indeed vote leave but so too did many of the relatively well off and comfortable in the tory shires. Here, too, there was fear, but now seemingly mixed with a nostalgia for a world long gone, and an apprehension about the world outside, in line with the somewhat traditional insular patriotism of this group. There was also evident an insularity of a different sort among the metropolitan elites who voted remain . Uprooted by their education and away from family, locality, a sense of belongingness, tradition, and not fully aware of the dynamics of the sother Britain, they were bewildered that the result was even possible. Certainly in the aftermath of the referendum many in Britain felt, and still to some extent feel, wounded. Thousands of , Remain voters reported feeling bereft, cheated, even bereaved by the wresting away of what they had hitherto taken for granted: their place in an open and communicative world with freedom to work, travel, and culturally share as well as being receptive to the other. To use a Jungian analogy, on the morning of 23rd June it was as if Remain voters not only came face to face with their shadow, but contrary to all wisdom, common sense, and standard therapeutic advice, had allowed it the keys to their car.

${ }^{10}$ Grayson Perry, "All Man«, UK Channel 4 TV, see http://www.channel4.com/ programmes/grayson-perry-all-man/videos/all/s1-ep2-top-dog/4890507922001 
threat, loss, and even possible death. Solomon et al, however, suggest there could be potential benefits in becoming more explicitly aware of our mortality, in developing what they call a sproximal awareness of death, and while not morbidly entertaining thoughts of death, of reaching out compassionately to others having accepted our own and their mortality. At best, making death a friend of sorts might take away its sting, at worst, keeping death in the shadows clearly leads to a life of fear.

\section{Nurturing ethical beings}

Our attitude to damage and death can, however, have moral consequences, and Darcia Narvaez's work helps illuminate some of these. ${ }^{11}$ Her theory asserts that how we cope with our vulnerability has positive or negative implications for our wider encounters with the world and our fellows. Our coping can bring us closer or push us apart, or even point to ways of transcending our fragility and mortality. Perhaps it can even suggest to us how to escape from the seemingly inevitable connection of vulnerable as wounded and as wound-er.

As part of her overall theory of moral expertise, Narvaez and colleagues have developed the >Triune or >Multi-Ethics Theory to explore different, human, normative moral responses, as some people retreat defensively, some engage positively, some respond imaginatively and courageously in complex, threatening, or conflicting moral situations. Their work rests in part on the increasingly well established idea that moral responses are akin to skilled behaviours acquired through imitation and learning. Noting that humans develop and grow their moral abilities, Narvaez maintains that they do so from different initial genetic and early experiential conditions, some of which, and in combination, are more helpful for moral development than others. Hence there are optimal ways for humans to acquire moral expertise. Conversely, some rearing situations and learning patterns are morally sub-optimal. A second axiom is that such learning shapes the sorts of brains and nervous systems we eventually come to have. Being neither fixed nor completely lacking in structure at birth, pathways grow and develop through

(accessed 17th October, 2016). See also Grayson Perry, The Descent of Man, London 2016.

${ }^{11}$ Darcia Narvaez, Neurobiology and the Development of Human Morality: Evolution, Culture and Wisdom, New York 2011. 
a process of strengthening and pruning of neural connections, or wither and weaken through disuse, pathways which eventually exert control over our default responses to moral situations. Multi-Ethics theory further identifies three constellations of ethics hypothetically associated with the tuning of different brain systems. Each system is variously developed as a result of different child rearing practices, and differentially supports a number of psychological aptitudes including perception, cognition, the perceived possibilities for action and goals and so on. Narvaez labels these the Ethic of Safety, the Ethic of Engagement, and the Ethic of Imagination.

Ethics of Safety, essentially concerned with issues of survival, are shared with all mammals and present instinctually from birth. Relying on brain systems concerned with basic emotional responses and action, and reinforced through somewhat negative or even punitive rearing patterns, we might think of these as governing the standard ifight-or-flight response of traditional psychobiology. Add to this the governance of behaviours involving territoriality, power struggles, maintenance of fixed precedents and routines, and we have the basis for a self-protective system of proto-morality. In group/outgroup differences are accentuated as defences are erected, hierarchy and pecking order emphasized, and a mob mentality encouraged. The petty criminals and drug dealers interviewed by Grayson Perry illustrate this response pattern to perfection as they seek their own flourishing through wealth, power, and status. While contemptuous of those from another spatch they simultaneously seek to protect their own from attack by others. A person operating under the Safety Ethic is essentially in a self-protective mode as neuro-cognitive resources are drawn away from higher order functions and activities such as empathy or compassion. The Safety Ethic is thus revealed as our most basic tactic for coping with the inevitable connection between our finitude and our vulnerability, as creatures that can be wounded, but also, sadly, can wound. It is not difficult to see this as the likely default setting for many of the terror management responses uncovered and explicated in detail by TMT researchers.

Engagement Ethics, by contrast, are expansive and develop where parenting is secure, safe, and affirming, and where early life experiences less stressful. They depend on (often right hemisphere) brain systems that support relationality, appropriate emotionality, empathy, and intimacy. The foundations of trust and love are laid as such systems are strengthened helping foster the values of tolerance, compassion, and openness. The crucial aspect of the Engagement Ethic, then, is that the healthy emotions on which it depends open up the 
self to the world and others in a positive way, instead of turning it negatively and protectively inward as with the Safety Ethic. Agreeing with Narvaez, we might see the beginnings of wisdom as rooted in the Engagement Ethic, especially when it fosters compassion. In all individuals at different times, orientations of safety or engagement will come to the fore, but Narvaez's key insight is that one or other can come to predominate in an habitual way as a result of the shaping effect of experiences during development. We can repeatedly turn outward to the world and to others, or inward to our selves, our in-group, our tribe, or our nation. Once again the relationship with the dynamics and attitudes evident in UK's brexit vote is suggestive. Those voting remain', on the surface at least, appear to be more characterized by an Engagement Ethic, though the subsequent withdrawal of some into social groups of like-minded individuals on social media for safety suggests the situation is more complex.

But there is more: the Imagination Ethic. As with the Engagement Ethic, the Imagination Ethic depends on good parenting, this time to help develop frontal and pre-frontal cortices, areas known to be involved with prospection, planning, and meta cognition. Whereas, for Narvaez, Engagement and Safety Ethics are largely intuitive and pre-reflective, the Imagination Ethic helps consciously co-ordinate these. It deals too with the often conflicting and multiple goals and emotions in moral perception, judgment, and decision-making in an equally aware and deliberative fashion. The Imagination ethic, according to Narvaez, is especially suitable for developing an awareness and appreciation of larger communities extending beyond proximal relationships. It liberates us from our narrow tribes, even attractive and engaging ones! It is the ethical sense needed for others, as well as oneself, and we expect it will be required to exercise moral creativity, as we step back to envisage creatively alternative futures and try to discern their worth. Once again this response style can also be for good or ill, as the fact that those with such skills can press their imaginations into vicious service makes abundantly clear. Overall, however, it appears to be in our interest as individuals and as species to develop the moral imaginations needed to transcend our more basic responses to our vulnerability.

If this overall approach is broadly right, judgment and intuition, emotions, moral narratives, and imagination are all shaped into components of moral expertise through action and interaction with significant others. Moral expertise in the broadest sense appears to grow and develop as a result of our interpersonal and familial relationships, and as a function of our cultural situated-ness in ethical 
communities or moral orders as Christian Smith, ${ }^{12}$ Alasdair MacIntyre $^{13}$ and others have cogently argued.

\section{Moral imagination and creativity}

Suppose then, for the sake of argument, that imagination and moral creativity are needed to transcend our more basic psychological settings, of safety and (group) engagement, which characterize us all as vulnerable, dependent creatures, what then are their characteristics? Work in this area is still in in its infancy, but it is possible to discern some suggestive directions extrapolating first from recent work in cognitive science to moral behaviour.

\section{Habit and creativity}

Creativity is often seen as antithetical to habit and tradition. The latter are frequently viewed as retrogressive conservative forces, as in the force of habit or the dead weight of tradition, whereas creativity, often associated with the lone thinker or genius, is said to be marked by novel breaks or ruptures from what has gone before. In contrast, as Vlad Petre Glăveanu argues, high levels or expertise or skill can in suitable circumstances give rise to unpredictable improvisation and innovation, and are often required for them to occur. ${ }^{14} \mathrm{Jazz}$ pianists, for example, are skilled musicians who can improvise new themes, master crafts-persons or architects, say, abide by the rules yet make innovative artefacts or produce stunning new designs. And what is true for perceptual-motor or cognitive expertise, is likely to be true too for moral creativity. Hence, we can expect a suitable training in, and facility with, virtue, understood here as moral expertise, to be an important foundation for the eventual emergence of moral creativity. Why is this? It is because moral orders are precisely the advanced schools of virtue needed to support and develop virtuous practices par excellence. Moral creativity will most likely emerge from such robust moral orders and traditions, and then help us improve

12 Christian Smith, Moral Believing Animals: Human Personhood and Culture, Oxford 2003.

${ }^{13}$ Alasdair MacIntyre, AfterVirtue: A Study in Moral Theory, London ${ }^{2} 1985$.

${ }_{14}$ Vlad Petre Glăveanu, Habitual creativity: revising habit, reconceptualising creativity, in: Review of General Psychology 16/1 (2012), 78-92. See also Vlad Petre Glăveanu, Rewriting the language of creativity: the Five A's framework, in: Review of General Psychology 17/1 (2013), 69-81, for more context. 
and even transcend them. As well as the sort of nurturing familial environments that Narvaez refers to, moral creativity (in the virtuous and not vicious sense) will thus depend even more on supportive social contexts. At best, then, we are moral, social, and historical beings shaped by our dispositions and situatedness, schooled in virtue, and ready to become moral virtuosi. Moral expertise is not merely the bedrock of moral creativity, but an essential component of it such that creativity is its highest expression, with moral creativity signifying less a break with the past than the imaginative projection of its possibilities for the good into the future.

\section{Prospection and imagination}

To act and think creatively is to envisage possible futures. Our ability to think deliberately prospectively is a key distinguishing feature of our species. For years, however, in its desire to emulate the physical sciences, psychology has been locked into a positivist causal mindset in which current behaviour, mental life, or emotion are construed as all due to past influences. This is true whether we are discussing Freudian psychodynamics, Skinnerian behaviourism, or even large tranches of first generation cognitive psychology. The situation is now changing. Ideas and evidence that have been accumulating for decades are at last seen as pointing to the vital fact that we are as much future-oriented beings as we are past-driven ones. Prospective thinking, according to the recent ground breaking work of Martin Seligman, Peter Railton, Roy Baumeister and Chandra Sripida, permits controlled counterfactual thinking but also imaginative envisioning of possible futures, and evaluation of their value. ${ }^{15}$

Again we can go further: imaginative envisioning of this sort will not merely entail analytic thought, poetics will also frequently be its hallmark. Art often precedes rrational discovery, after all, and the aesthetic sfittingness of its outcomes will commonly attract more than the pragmatic or functional utility of any supposed ssolution', as peace theorist John Lederach has also eloquently shown. ${ }^{16}$ Thus, analogy, parable, haiku, painting, metaphor will often figure among the true signs of moral creativity.

\footnotetext{
15 Martin Seligman/Peter Railton/Roy Baumeister/Chandra Sripada, Homo Prospectus, Oxford 2016.

${ }^{16}$ John Lederach, The Moral Imagination: The Art and Soul of Building Peace, Oxford 2005 .
} 


\section{And religion?}

Given all this, might religion offer just the sort of ordered rationality needed to support training in virtuous practices? Can it offer precisely the sort of mental, emotional, aesthetic, and metaphysical support required for the liberating, creative prospection essential for escaping our default moral settings? In this way, does it help us transcend our moral and mortal vulnerability?

Here we have either a reduction that takes us back to our beginning, or a paradox. Read simply through the reductive lenses of Becker and TMT, religion is nothing but a cultural framework which evolved, and to which its adherents cling, for protection against the fear of death. It is, in other words, merely a culturally constructed system providing a more sophisticated psychological illusion and protection than even Freud envisaged. It does this by offering, somewhat speciously, a protective god, a socio-cultural tribe or in-group as comfort, and a promise of immortality or severlasting life. Such religion can only be seen to reinforce, but never to qualify nor attenuate, our default moral and psychological responses. Or, on an equally reductive interpretation, this time based on the cognitive science of religion, religion is merely a by-product of cognitive mechanisms, a matter of psycho-biology originally evolved for other reasons, but again without mereological depth, concern for truth-value, or intrinsic meaning.

Suppose instead that serious religions are socio-cultural systems with more foundation than this, with more ontological bottom we might say. Suppose they permit, in principle at least, the growth of a courageous moral and spiritual creativity in the face of accepted death and vulnerability. Here I can only speak from experience and knowledge of one, albeit major, branch of the Christian tradition, Roman Catholicism.

The pre Vatican II Catholicism of my childhood had many flaws; perhaps it was rightly called the religion of the cross, but my schooling and moral formation did at least four things moderately well. First it acknowledged death; it never hid it, nor hid from it. From prayers , for the one amongst us who will be the first to die< to the wonderful (if sadly gendered) liturgy of Ash Wednesday, $>$ Remember man that thou art dust and unto dust thou shalt return', to the sombre, black vestments of a Requiem Mass, in TMT terms we were repeatedly made proximally aware so our mortality. Death was real, not sanitized. People did not 'pass away`, or 'move into the next room<, they ceased to exist as embodied and socially embed- 
ded, temporal entities. They died. The world and we were obviously transient. "In your sight the whole world is like a grain of dust that tips the scales, like a drop of morning dew falling on the ground. « $^{17}$ Second, the fact of the Resurrection was frequently emphasized as a living mystery, not a conjuring trick with bones, as we were taught that it was only through self-sacrificial (holy-making) death of all sorts that new life could emerge. Death was not so much a station on a two-world, inter psychic railway to theme park heaven, but a necessary breaking down of self before reconstruction into self-lessness could happen - now and not yet.

But this was not all. It was made clear from the beginning that the prime directive was to love God and one's neighbour as oneself. Whatever the merits of American sself-esteem culture`, pride, the wrong sort of pride, was clearly a sin. Period. As school students we were encouraged carefully to distinguish between a healthy sense of self-worth, and a puffed up, self aggrandized, beggar-my-neighbour attitude. Doubtless we often failed, but the automatic default into the self-affirming, self-congratulating self, beloved of TMT, was not there, at least not as an official escape route. Moreover, we were taught time and time again (without precisely these words being used) that there were no in-groups or out-groups in the Body of Christ or the Kingdom of God. This was a place where there is neither male nor female, Jew nor Greek, slave nor free, again despite the often divisive antics of the official church. Another TMT escape route was blocked. Finally, the ritualistic clinging to religion as an obsessive safety blanket was often discouraged, though it has to be said not invariably or always successfully. TMT exit three closed. Taken together, then, the combination of folk religion and >officiak religion of my boyhood offered, we might say, a frequently practiced and internalized cognitive, affective, and behavioural training to counteract default TMT settings. On a good day it might even have worked.

So much for the sofficial Christianity, which transmutes at times into 'folkı religion. ${ }^{18}$ But perhaps, one might say, as a cultural system Christianity still offers the comforting illusion of immortality as a means of cheating death. Maybe it sneaks in just such a meaning system as analgesic after all, as Becker and others have suggested. Maybe. Suppose, however, that the serious metaphysics of religion corrected

17 Wisdom 11,23, scriptural references from The Jerusalem Bible, London 1966.

${ }^{18}$ See Jonathan Jong, Ernest Becker's psychology of religion forty years on: a view from social cognitive psychology, Zygon 49/4 (2014), 875-889, for more on this distinction. 
of the excesses of some of its official or 'folk « versions does not offer as a sop a godlet understood as a being among beings who occasionally fixes things, does not confuse vitam aeternam (eternal life) with reverlasting`, does not offer easy solutions or panacea, where are we then? Suppose, following Eckhart and others in the mystical tradition, as Denys Turner and others have skillfully argued, we are led even to snegate the negation and manage to let go of all idolatrous images of God, whether positive or negative. Then and only then do we realize that God is not reducible to a contingent experience or cognition, ${ }^{19}$ and that death itself is always already uniquely out manœuvered by that which supports all life. Perhaps we then arrive right at the imaginative heart of orthodox, premodern, Christianity. Following Cusa, as Johannes Hoff among others has shown, ${ }^{20}$ here is a paradoxical place of coincidentia oppositorum, one where everyday particularity and the general/universal coincide, where with Blake we see reternity in a grain of sand, where the transcendent is immanent once more, where being is held in being, and hence where this fleeting moment dies (if it ever existed independently at all), yet always eternally lives. Here is a place where death is not sanitized, and its full horror and inevitability are acknowledged and accepted, but where it simply cannot have the final word; for that would be to eclipse if not destroy completely all meaning, language, and being itself. And in their dying and extinction, death's last word would also die, as it also ceased to be. Indeed for death to happen at all (but not finally succeed), life, meaningful life, must be underwritten and guaranteed, even as its transient morning dew falls on the dust. Orthodox Christian believers may thus courageously face death allowing it to collapse into contradiction, formless chaos and die, while trusting in the knowledge that life will inevitably if paradoxically rise again, as we affirm:

"Yes, you love all that exists, you hold nothing of what you have made in abhorrence, for had you hated anything you would not have formed it. And how, had you not willed it, could a thing persist, how be conserved if not called forth by you? You spare all things because all things are yours, Lord, lover of life, you whose imperishable spirit is in all. $\|^{21}$

\footnotetext{
${ }^{19}$ Denys Turner, The Darkness of God: Negativity in Christian Mysticism, Cambridge 1995 .

${ }^{20}$ Johannes Hoff, The Analogical Turn: Rethinking Modernity with Nicholas of Cusa, London 2013.

${ }^{21}$ Wisdom 11,24-27.
} 
Seeking to emulate and participate in this simperishable spirit Christians aim to model the perfected divine-human exemplified in Christ. In following Him we are not, of course, immune from being wounded and hurt, but in approximating his perfection we try, at last, to be vulnerable without wounding others in turn. And, since "you [...] even fashioned for us a remedy out of mortality itself", and when having seemingly lost everything, "dying you destroyed our death $\aleph^{22}$, so with post-humous vision, vision beyond the dust, but not beyond the stars, we too find eternal life.

- Peter Hampson, Emeritus Professor of Psychology, University of the West of England, Bristol, and (Adjunct) Honorary Professor of Psychology at the National University of Ireland, Maynooth, is currently a Research Fellow at Blackfriars Hall, Oxford University. He has degrees in both theology and psychology and his scholarly and research interests include moral psychology, theology-psychology dialogue; religion, theology and interdisciplinarity in higher education; theology and literature.

${ }^{22}$ Roman Catholic liturgy of the Mass, Preface, 28th Sunday in Ordinary time, Cycle C. 